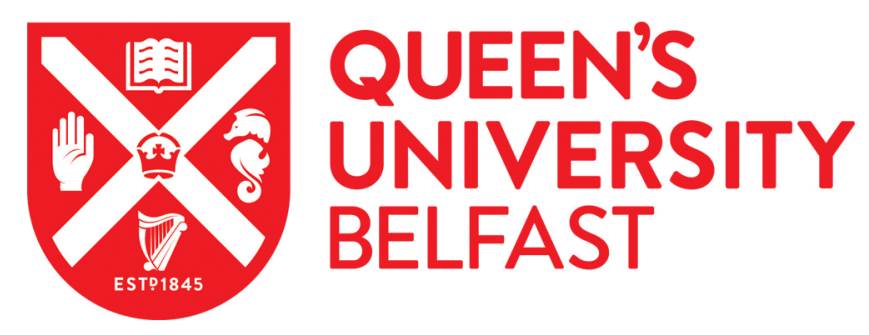

\title{
The role of place on healthcare quality improvement: A qualitative case study of a teaching hospital
}

Moutinho Barbosa de Melo, S. (2018). The role of place on healthcare quality improvement: A qualitative case study of a teaching hospital. Social Science \& Medicine, 202, 136-142.

https://doi.org/10.1016/j.socscimed.2018.03.003

\section{Published in:}

Social Science \& Medicine

\section{Document Version:}

Peer reviewed version

\section{Queen's University Belfast - Research Portal:}

Link to publication record in Queen's University Belfast Research Portal

\section{Publisher rights}

Copyright 2018 Elsevier

This manuscript is distributed under a Creative Commons Attribution-NonCommercial-NoDerivs License

(https://creativecommons.org/licenses/by-nc-nd/4.0/), which permits distribution and reproduction for non-commercial purposes, provided the author and source are cited.

\section{General rights}

Copyright for the publications made accessible via the Queen's University Belfast Research Portal is retained by the author(s) and / or other copyright owners and it is a condition of accessing these publications that users recognise and abide by the legal requirements associated with these rights.

Take down policy

The Research Portal is Queen's institutional repository that provides access to Queen's research output. Every effort has been made to ensure that content in the Research Portal does not infringe any person's rights, or applicable UK laws. If you discover content in the Research Portal that you believe breaches copyright or violates any law, please contact openaccess@qub.ac.uk. 
2 This article examines how the built environment impacts on, and is impacted by, healthcare staff day to day practice, care outcomes and the design of new quality and patient safety (Q\&PS) projects. It also explores how perceptions of the built environment affect inter-professional dynamics. In doing so, it contributes to the overlooked interplay between the physical, social, and symbolic dimensions associated with a hospital's place. The study draws on 46 in-depth semi-structured interviews conducted at a large teaching hospital in Portugal formed by two buildings. Interview transcripts were analysed inductively using thematic analysis.

9 The major contribution of this study is to advance the understanding of the interactions among the different dimensions of place on Q\&PS improvement. For example, findings indicate that

11 some of the characteristics of the physical infrastructure of the hospital have a negative impact 12 on the quality of care provided and/or significantly limit the initiatives that can be implemented to improve it, including refurbishment works. However, decisions on refurbishment works were 14 also influenced by the characteristics of the patient population, hospital budget, etc. Likewise, clinicians' emotional reactions to the limitations of the buildings depended on their expectations of the buildings and the symbolic projections they attributed to them. Nevertheless, differences between clinicians' expectations regarding the physical infrastructure and its actual features influenced clinicians' views on Q\&PS initiatives designed by non-clinicians. 


\section{Introduction}

Hospital spaces have been researched mostly by health geographers, environmental psychologists and architects, adopting the perspective of hospitals as environments with an impact on patients' recovery and healing (Gesler et al., 2004). According to Gesler et al. (2004:119), these 'therapeutic environments' must not merely consider the physical space, but instead should take into account the "physical environments (both natural and built), social environments and symbolic environments". This is in line with the social theory perspective of space which considers the spatial and the social as two intertwined components of place (e.g.

Casey, 1996; Dovey, 2010; Gieryn, 2000, 2002; Heynen, 2013; Lefebvre, [1974] 1991; Massey, 1994). As Dovey (2010:3) argues, “[a] large part of what distinguishes place from space is that place has an intensity that connects sociality to spatiality in everyday life".

The small number of previous studies exploring the role of place on quality and patient safety (Q\&PS) have recognised the physical infrastructure as a means of communicating expectations in relation to how staff should perform their clinical activity (e.g. Fox, 1997; Hujala and Rissanen, 2011), and as a symbol of differences in value attributed to different professional groups (e.g. Halford and Leonard, 2003), types of diseases (e.g. Sullivan, 2012), and between nursing home residents and staff (e.g. Hujala and Rissanen, 2011), as well as how these differences in value frame patients' (e.g. Sullivan, 2012) and clinicians' identities (e.g. Halford and Leonard, 2003). Extant research has also identified the role of refurbishment works as a way of engaging staff in a quality improvement project (e.g. Gorbenko et al., 2015) and explored the impact of the physical infrastructure on the quality of care provided and relationship between doctors and patients (e.g. Zhou and Grady, 2016). 
1 However, despite the recognition of hospital places as physical, social, and symbolic environments; most of the literature on Q\&PS has either focused on the role of the physical environment as an instrument with the power to change clinical practice and care outcomes or

4 has emphasised the influence of hospital procedures on Q\&PS improvement while considering 5 the physical environment as a receptor of such initiatives. Following Ulrich's (1984) pioneer 6 study evidencing the restorative effect of a room with a natural scene (i.e. trees) compared with a 7 brick wall window view on hospitalised surgical patients, a significant number of studies have 8 aimed at identifying and applying evidence-based designs in order to maximize organisational 9 and clinical performance (Mallak et al., 2003). In a comprehensive literature review conducted 10 by Ulrich et al. (2008), the authors found evidence that the quality of the aesthetic aspects of the 11 physical design (e.g. ward layout, window view, floor and furniture coverings, ventilation and 12 water-supply systems) not only influences the quality of clinical spaces (e.g. air quality; 13 cleanliness of floors, walls, furniture, etc.) but has also an impact on clinician's behaviours, thus impacting on the clinical quality of care provided and care outcomes (e.g. hospital-acquired infections, patient falls, length of stay). By solely focusing on the functional qualities of architecture associated with the physical environment (Buffoli et al., 2012), evidence-based design research overlooks the symbolic and social environments, which are core defining components of place (Dovey, 2010; Lefebvre, [1974] 1991). By contrast, a significant body of literature emphasizes the influence of management decisions, organisational procedures, and professional socialization processes on Q\&PS improvement but

21 considers the physical environment as the receptor or background of such activities. For example, on Reason's (2016) organisational accident model, poorly designed facilities are part of 23 latent conditions - conditions considered to create weaknesses but which are only revealed when 
1 active failures occur. The built environment is thus implicitly assumed as the 'context' of unsafe actions (errors and violations) of the people involved in the system (Reason, 2016). Similarly, on

3 Donabedian's structure-process-outcome framework for the assessment of the quality of care,

4 structure - which includes the facilities - is "meant to designate the conditions under which care

5 is provided" (Donabedian and Bashshur, 2003:46). Although this might seem a reasonable

6 observation, by considering the physical infrastructure as the background of social activities, the

7 impact that it has on the social environment is largely ignored (Heynen, 2013). Other studies

8 acknowledge the embodied nature of clinical practice and investigate how the spatial relationship

9 between the body of the clinician and the patient-body shape clinical practice and the meanings

10 and symbolism associated with it (e.g. Gardner and Williams, 2015; Moreira, 2004). Yet, they

11 overlook the physical environment within which clinical practice takes place and therefore fail to

12 recognize the active influence of the physical environment in framing clinician's and patient's

13 behaviours. Similarly, some studies (e.g. Bosk, 2003; Rosenthal, 1995) recognise the importance

14 of a hospital's social environment on Q\&PS by exploring how professional socialization

15 processes influence safety issues, but also do not explicitly consider the role of the physical

16 environment.

17 Q\&PS studies adopting what Heynen (2013) identifies as space as instrument or space as receptor models can only provide a partial account of the role of place on Q\&PS; an in-depth understanding requires taking into account the interactions between all three dimensions of place. Therefore, there is the need to consider the physical infrastructure as the stage of the social

21 and symbolic environments, which is the perspective adopted in this article. In the space as stage model, which integrates the space as receptor and space as instrument models, the built environment is perceived as "conditioning, structuring or framing social behaviours without 
really determining them" (Heynen, 2013:350). Therefore, "buildings are an integral element of structuration and reproduction" (Gieryn, 2002:37) as buildings are forces that structure social practices but human agency also has a role in the shaping of buildings (Gieryn, 2002). As a result, underlying the space as stage model is the conceptualization of space as a "precarious achievemen[t] made up of relations between multiple entities" (Anderson, 2008:230), as physical, social, and cultural processes that make space are themselves dialectically/relationally constructed (Harvey, 1996). Space is thus subject to 'dynamic becoming' and constant change (Thrift, 1996), rather than a fixed entity.

9 The main contribution of this study is to advance the understanding of the interactions between the physical, social, and symbolic dimensions of place (Hujala and Rissanen, 2011) by adding to

11 the few empirical healthcare studies that have explored these, and even fewer in the context of 12 Q\&PS (Martin et al., 2015). Specifically, this article explores how the physical environment 13 impacts on, and is impacted by, the social environment, by looking at its influence on healthcare staff day to day activities, including how Q\&PS is realised; care outcomes, the design of Q\&PS projects, and the cultural significance of Q\&PS. In addition, this article also explores the interplay between clinicians' expectations and symbolic projections in relation to the hospital's infrastructure and the limitations of the buildings, as well as how these affect interprofessional dynamics. In doing so, it responds to calls for further research exploring how hospital buildings contribute to patient safety (e.g. Mesman, 2012), how they are experienced and daily used (e.g. Martin et al., 2015) and how hospital places influence healthcare workers (e.g. Andrews and

21 Evans, 2008).

\section{Methods}

\subsection{Context and case study}


1 This article is based on a case study conducted in a purposefully chosen large teaching hospital

2 part of the Portuguese National Health Service. A case study was chosen because this study

3 design can usefully provide a rich description of the complexities of a situation and thus

4 contribute to the understanding of a greater phenomenon (Rossman and Rallis, 2003). At the

5 time of data collection, the hospital was identified as one of the pioneer hospitals in Portugal to

6 formally embark on Q\&PS improvement initiatives. After an informal visit to present the study

7 to the hospital, arranged through personal contacts working at the hospital, and the confirmation

8 of the hospital's willingness in participating in the study; the first author obtained ethics approval

9 from both the hospital and from University X where they were based.

10 The hospital consists of two buildings. One of the buildings, known in the hospital as the

11 neoclassical building, was designed in 1769 and is based on a project prepared by the British

12 architect John Carr. Part of it started to function on 19 August 1799. Although the processes of

13 designing the floor plan and construction are not the object of this research, it is worth noting

14 that when Carr designed the building he thought that because brick was the material that would

15 have been used in England, it would be used in the hospital. Instead, granite, as customary in

16 Portugal, was chosen. As discussed in the findings section, the use of granite instead of brick

17 resulted in the construction of an architectonically solid building, impeding any structural

18 alterations of the physical infrastructure. Given its rich architectural value the building is listed

19 as an object of national heritage. The other building, known as the Luís de Carvalho building,

20 was constructed from 1993 onwards, although it had been designed 15 or 20 years before, and

21 was inaugurated in 1998. The two buildings, very distinct in terms of architecture and physical

22 infrastructure, are linked by a central corridor.

23 2.2. Data collection 
1 Data were collected by the first author mainly through individual face-to-face in-depth semi-

2 structured interviews. Given that the hospital was previously unknown to the interviewer,

3 interviews took place in two stages. The first stage of eight interviews involving nine interviewees

4 took place in June 2009. These interviews aimed at exploring the reasons for the hospital's growing

5 interest with Q\&PS, the projects adopted, and understand the role and involvement of the different

6 departments and staff. Based on this contextual information, two projects were selected as the

7 subject of analysis on the second stage of interviews: the improvement of the hospital's

8 accessibility and falls prevention. The second stage of 38 interviews took place between December

92009 and January 2010 and involved 41 interviewees. These interviews aimed at exploring the

10 underlying factors that led to the adoption of those specific Q\&PS projects, how the projects

11 evolved, who was involved, and the organisational factors that contributed or created barriers to

12 the projects. Although the role of place on Q\&PS improvement was evident in both interview stages, its relevance only emerged while analysing the data. During the first stage of interviews, the physical infrastructure was mentioned by interviewees when asked about the factors that influence Q\&PS. The second stage of interviews included a general question on the role and importance of non-human factors (e.g. buildings, equipment, information systems, written procedures, etc.) on the different stages of the two Q\&PS projects in analysis.

Overall, 46 interviews with 49 interviewees were conducted. Interviews were conducted with nurses (25), doctors (8), nurse aides (4), engineers (3), administrative staff (2), health and safety technicians (2), managers (2), social workers (2), and laboratory technician (1). Interviewees 21 worked at internal medicine (12), general surgery (10), cardiology (5), accidents and emergency 22 (5) and other clinical departments (5), the quality management department (6), premises and 23 equipment (1), sterilisation (1) and other non-clinical departments (4). One of the interviewees was 
1 interviewed in each of interview stages, in view of their role as a key informant. The interviews 2 lasted from 12 to 120 minutes, the average duration being 43 minutes. The variability in interview 3 length reflects differences in staff's involvement and awareness of Q\&PS projects. Interviews of 4 short duration were mainly carried out with staff that either did not have a direct role on Q\&PS 5 projects (e.g. administrative staff) or were only familiar with some aspects of these projects (e.g. 6 nurse aides). All the interviews but four were individual interviews. Interviews with two 7 professionals took place due to pragmatic reasons relating to office sharing and professionals' time 8 constraints. In these cases, the researcher never felt that conducting joint interviews inhibited any 9 interviewee's participation.

10 Interviews took place in the hospital at a convenient time for interviewees and were conducted in 11 Portuguese, the native language of all the interviewees and of the interviewer. Interviewees were 12 approached using a combination of purposive and snowball recruitment strategies. Although 13 individual interviewees were identified through snowball sampling, the interviewer purposively 14 asked interviewees to suggest colleagues from different departments in order for the sample to reflect the diversity of hospital departments. In each of the stages, all interviews followed the same interview guide, but not all interviewees were asked the same questions. During the

17 interviews the question to ask next was chosen according to the answers given by the 18 interviewees to previous questions.

19 All interviews (with the exception of two) were audio-recorded and transcribed verbatim by the 20 first author. In the two interviews where interviewees preferred to not be recorded, detailed notes 21 were taken. Before the start of each interview the aims and objectives of the study were verbally 22 explained, an information sheet with the details of the study was given and written informed 
1 consent was obtained from the interviewee(s). Whilst the hospital allowed the use of its name, all

2 the quotations were anonymised and sometimes slightly changed in order to ensure anonymity.

3

4 Transcripts were analysed by the first author following Braun and Clarke's (2006) guidelines for

\subsection{Data analysis}

thematic analysis. The process of coding and identification of themes and sub-themes followed an inductive approach (Braun and Clarke, 2006). Data were coded at semantic level and the analytic process involved the description and interpretation of data with a focus on interviewees' accounts of their experiences and the meanings they attributed to them (Braun and Clarke, 2006). Coding was performed manually, by writing notes on the transcripts and using highlighters, with the aim of avoiding fragmentation and decontextualization of the data (Webb, 1999). Initial codes were generated from the data and often based on interviewee's own words. Relevant coded extracts were copied into a separate Microsoft word file. The codes were reviewed and clustered into initial sub-themes and themes which were then refined through the use of visual thematic maps (Braun and Clarke, 2006).

Interview data were supplemented with information from informal conversations, statistics, annual reports, hospital accreditation manuals, information published in magazines and on the hospital's website, and documents from the Portuguese Ministry of Health. Access to data sources not available online (i.e. statistics and accreditation manuals) was obtained from the interviewees. The information publicly available was directly sourced by the interviewer. These documents were read and notes on the hospital's Q\&PS projects were taken.

The data were analysed in Portuguese. Quotations used in the article were translated into English by the interviewer in order to ensure the anonymity of quotations and avoid distortions in the meaning. A few weeks after the translation, the interviewer back translated the quotations to 
ensure its quality. In order to improve the truth value of the research, several other strategies suggested by Rossman and Rallis (2003) were applied in this study. Namely, a large volume of data was gathered over a long period of time and during the data collection factual interpretations by the researcher were checked with the interviewees; the study was designed and conducted with a focus on participation; triangulation of different qualitative methods was used to obtain a more in depth knowledge about the case study and to assess the consistency of the findings drawn from different methods (Flick, 2007).

\section{Findings}

9 The analysis of the findings identified that the interactions between the physical, social, and 10 symbolic environments had a key influence on Q\&PS improvement, hence reinforcing the need to 11 further understand the role of place on Q\&PS. As presented below, in the case study hospital, the built environment had an impact on the quality of care provided and on the design and implementation of Q\&PS initiatives. However, the built environment also shaped how Q\&PS is realised, its cultural significance, as well as influenced staff's symbolic projections, expectations and emotional reactions towards the built environment and Q\&PS initiatives.

\subsection{The impact of the built environment on the quality of care provided}

17 Consistent with research on patient falls (e.g. Hignett et al., 2015), several interviewees pointed out features of the buildings as contributing factors to patient falls. The two architectonic characteristics of the Luís de Carvalho building mentioned most by interviewees were the slippery floor coverings of the toilets/bathrooms and the shower trays: free movement of the wheelchair. In the case of the shower this was really problematic 
when there were slippery floorings $[\ldots]$ the risk [of falling] increased even further. (Nonclinical member of staff)

3 A clinical department located in the neoclassical building reported falls which identified the unevenness of the floor as a risk factor. Patients with reduced mobility can trip and fall over every slight unevenness between the granite blocks: In the neoclassical building [...] the whole structure is in stone $[\ldots]$, and in some corridors there is no floor [covering]. [...] The irregularity in flooring can often cause [elderly patients] some trouble. (Nurse)

9 These examples demonstrate that the built environment has a critical role on patient falls, which is in line with a significant body of nursing and human factors research that has pointed out specific

11 extrinsic factors such as layouts of clinical units, rooms, and toilets; flooring materials, and

12 flooring irregularities as fall risk factors (e.g. Hignett et al., 2015).

14 The physical infrastructure was also often mentioned by interviewees as having a significant 15 impact on Q\&PS initiatives. Several alterations to the physical environment became the focus of 16 Q\&PS activities when staff realized that they constituted hazards to patient safety. For example, 17 in the sequence of the notification of falls caused by the unevenness of the floor, the hospital contracted workers to eliminate it: In the neoclassical building [...] about two years ago some construction workers were [in the hospital] trying to join the granite blocks smoothly [in order] to improve the mobility of the elderly $[\ldots]$ who walked there. (Nurse) 
1 Likewise, the recognition of slippery floor coverings in bathrooms as a cause of patient falls made their replacement a high-priority Q\&PS project:

[On the basis of some notifications of falls] we were able to specifically correct what was happening in some services. One example was the slippery flooring in the bathrooms and we changed it. Many patients were falling [...] We changed the bathroom. We reduced the number of falls and their severity. (Doctor)

However, the fact that the neoclassical building is made of granite limited the scope of refurbishments:

... what we have are $[\ldots]$ architectural issues, structural and in some cases $[\ldots]$ insurmountable $[\ldots]$ because we are surrounded by granite that cannot be moved. Of course, for example, in the disabled [bathrooms/toilets] there are minimum conditions for wheelchair circulation inside the bathroom and so that has to be ensured. Beyond the minimum, we would like to be a bit more ambitious but in some cases we are really limited to the minimum because nothing more is possible. (Non-clinical member of staff)

Whereas the built environment influenced Q\&PS projects, these were also shaped by the social (e.g. budget allocation decisions) and symbolic environments (e.g. handrails as a symbol of greater support for patients):

We ended up taking steps to [remove the shower trays] and add anti-slippery floor coverings, supplemented with handrails to better support patients. It was a relatively simple measure and of course not very cheap, because of the number. We have about 200 sanitary facilities in the hospital and therefore you can see what that means in terms of investment. (Non-clinical member of staff) 
1 Additionally, because of its rich architectural value, the neoclassical building is listed as national heritage. This symbolism means that, in practice, the alterations that can be made to the building are limited and need prior approval by the Portuguese Institute of Architectural and Archaeological Heritage Management:

... and then we still have another problem which is the fact that it is a building with 210 years of history, at present... [the national] heritage has the regulatory authority, that [...] does not let us change [...] In cases where [the change] is for a good cause, even if we get authorisation, the answers and the approvals are slow [therefore it is complicated], you see?! (Member of the quality management department)

Alongside framing the focus and scope of some Q\&PS projects, the built environment also shaped how Q\&PS is realised, its cultural significance, and staff's symbolic expectations and reactions towards the built environment and Q\&PS projects.

\subsection{The impact of the built environment on how Q\&PS is realised}

During interviews, the physical infrastructure was often mentioned by interviewees as framing the way staff related with patients in order to achieve high Q\&PS. For example, some bed allocation decisions were influenced by the fact that the granite structure of the neoclassical building impeded the monitoring of patients:

The literature gives us the clues [to prevent falls] but, for example in the hospital [...] there is a wall that, for example, here [pointing to a place in the sketch of the ward layout which the nurse was drawing on a piece of paper] I can see the first three beds but I can't see the next three. So, it is like this: here I should not put fragile patients who need help because I know [...] I cannot put patients with these characteristics in a place where I 
can't see [them]. These [clinical] units where I am in the middle and I see almost everything are fantastic, but the infrastructure that we have, we have to [work with it] (Nurse)

This contrasted with a special area inside the accidents and emergency department as described by another nurse:

“... there are few patients, the room is wide so we have a much tighter [level of] monitoring, and also the ratio of nurses per patient is higher than in the wards, isn't it?! [...] So, that facilitates things a lot" (Nurse)

Both quotations point out that although the built environment had a key role on the quality of care provided, it did not determine it. It was its interaction with the social and symbolic environments (e.g. number of patients, patients/staff ratio, the possibility of seeing patients and the symbolism of closer monitoring associated with it), that affected clinician's actions and how Q\&PS is realised. As a doctor emphasised, when the physical infrastructure has limitations, there is the need to provide greater support to patients:

$[\ldots]$ there are things that it is not possible to change; the characteristics of the bathrooms, the slippery flooring or how the door opens which causes falls and therefore, of course that the support a patient needs in these services is much greater. (Doctor)

Likewise, a member of the quality management department stressed that although the existence of a good built environment facilitates staff's work and Q\&PS, its existence is not enough; it is necessary that staff use it appropriately:

Of course that those who have better infrastructure or have better resources can do their job in an easier way, so to speak, but this is not the only factor. [...] We 
can have the best equipment, the best infrastructure and then they be misused; and then [staff] complain that the equipment or the infrastructure are creating problems when in fact are professionals that are causing them [...] Thus, it is not enough to guarantee that the means exist, it is then [needed] to ensure that professionals use them in a correct and wise way. (Member of the quality management department)

Also, as a nurse described in relation to falls prevention, there is the need for all staff to work collaboratively:

All staff need to be alert to what may happen [...] Nurse aides support patients who have more difficulty in walking [...] follow the directions of the nurse responsible for that patient [In relation to doctors] when a patient is agitated, confused $[\ldots]$ often it is it is also necessary to prescribe medication so that the patient does not throw themselves out of the bed. [...] The administrative staff [...] are on the lobby [...] if someone with [mobility] difficulties arrives, they say 'look, be careful, you have a chair over there [...] sometimes they say [to us] 'look, there is a very debilitated person', etc. (Nurse)

Finally, irrespectively of the characteristics of the built environment or staff's behaviours, patients can still fall:

Sometimes [for a fall to take place] it is enough for the patient to be away from their home $[\ldots]$ The elderly wakes up during the night and thinks he is at home, tries to go to the toilet but simply he is in a completely strange place and the first thing that happens is to fall (Nurse) 
1 This relational view of Q\&PS as resultant from the interactions between the built environment,

2 staff, and patients, reinforces the need to adopt a space as stage perspective in order to understand 3 it.

\section{3.4. The impact of the built environment on the cultural significance of Q\&PS}

5 In the case study hospital, there was the recognition that Q\&PS depends on many factors. As two

6 clinicians commented in relation to factors that have an impact on falls:

I think that the physical infrastructure is a very important aspect, ah, the equipment, namely the beds, the type of beds, if they have or do not have side rails, the floor coverings, ah, these are aspects I consider to be important $[\ldots]$ of course the human part, professionals' awareness for this situation is also an [important] factor. (Nurse)

There are many pathologies that cause [falls]. For example diabetes can cause falls by many mechanisms; because it causes sight loss, or causes neuropathy. For example, it is natural for a patient with Parkinson's to have gait instability. A patient who had a stroke has a deficit [in the gait]. (Doctor)

As a result of this interaction of many factors, the identification of individual contributing factors such as the features of the built environment, required the reporting of a series of similar incidents:

We started to gather the [reported] falls and we started to realise that [...] patients were injured as a result of falls and no one had realized that they did not get injured by chance. They got injured because they always slipped in the same place in the bathroom [...] Sometimes recurrence and the compilation of a series 
of similar incidents is needed so we can find a common factor (Member of the quality management department)

3 This realisation that some of the factors underlying Q\&PS incidents are only noticeable with recurrent incident reporting led the quality management department to embark on a sensitisation campaign to the importance of incident reporting. The gradual increase in incident reporting across all staff groups led to the recognition of Q\&PS as a continuous process which requires the involvement of all staff, rather than just clinicians.

3.5. The impact of the built environment on staff's symbolic projections, expectations, and reactions

During interviews it was interesting to note how the opening date of each of the buildings framed

11 staff's symbolic projections attributed to each of the buildings and mediated staff's emotional 12 reactions towards the buildings' limitations and Q\&PS projects. Whilst the neoclassical building 13 was seen as an ancient and old-fashioned building; the Luís de Carvalho building, inaugurated in 14 the late 1990s, was perceived as a new, modern one; leading some hospital staff to refer to the two 15 buildings as if they were two different hospitals: ... in fact physical space is different, we have two hospitals, a modern one and another old. One is 200 or 300 years old; the other is 15 or 20 , hence they are two different realities. (Nurse)

19 The very fact that the neoclassical building was historic and had a history of helping the poor, 20 seemed to create a sense of admiration amongst the professionals: 
[In the past, particularly before the new building was built] everyone loved to work in the hospital, because it was old, poor, a friend of the poor, a friend of people, so it is a different hospital, and then because it is historical. (Nurse)

This feeling of affection translated into an acceptance of the neoclassical building as it was: [In] some situations there are structural and physical limitations that $[\ldots]$ in fact do not allow the ideal and so we have to go as far as possible [...] To compensate for that, we have the beauty of the building. (Member of the quality management department)

A very different situation applied to the Luís de Carvalho building. The simple fact that it was perceived as a modern building led to some unmet expectations and frustrations because of the architectural barriers that professionals did not expect to encounter. By contrast to the architectural barriers of the neoclassical building, the limitations of the new building were not generally accepted by professionals, particularly by nurses:

[About the Luís de Carvalho building] a hospital built from scratch, a new hospital, this hospital is new, it is 10 years old and all the patients' bathrooms have a shower tray, for example. There was no sensibility to certain issues... (Non-clinical member of staff)

Some hospital staff attributed the architectural shortcomings of the new building to decisions made by professionals and/or entities involved in the construction (e.g. engineers, architects) or the inspection of the building who, by contrast to them, lacked knowledge of the context of clinical practice:

[Regarding the new building] sometimes I have the impression that the engineers or architects might not be very ... aware of the disabilities and of the people who need help to move because our disabled bathroom which is [explicitly] labelled as a bathroom for 
3 Although it is outside the scope of this study, it is plausible to consider that several factors could

disabled people has a shower tray. So, it never crossed anyone's mind to put a barrier in a disabled bathroom ... and the building is only 10 years old. (Nurse) toilets/bathrooms of the Luís de Carvalho building. Just to mention a few possibilities, there was a fire in the neoclassical building at the end of 1976 which resulted in the loss of more than one hundred beds, hence stimulating the decision to put up an additional hospital building. The draft project of the Luís de Carvalho building was approved in 1983 and the final project was approved in 1986, a time when the hospital patient population had different characteristics from the population nowadays:

[At the end of the 1980s], the average percentage of hospitalised patients more than 65 years old was slightly more than $60 \%$. At present, the percentage of hospitalised patients older than 65 is nearly [...] 80\% [...] It is a quickly ageing population. (Non-clinical member of staff)

Nevertheless, clinical staff blamed other professionals for valuing aesthetics over functionality:

Some of the reasons for patient falls were related to the type of floor covering that the wards had, the type of floor covering that bathrooms had, the lack of handrails in the bathroom when patients were taking a shower; that sort of things. Now these were structural things $[\ldots]$ [even if] the institution was built from scratch, why would they end up making the same mistakes?! Because what would be beautiful was to have a very shiny floor covering or a very shiny wall, you see? (Nurse) 
1 During interviews, clinician's referred to procedures used by cleaners to deep clean the floor-

2 which were under non-clinicians' control - as a symbol that non-clinicians preferred aesthetics (a 3 beautiful clean floor) over functionality (a clean but safe floor):

Here in the service they are always doing floor maintenance. They deep clean every three months and everything is highly polished and we also think that it is slippery, but until someone falls and there is [an incident] ... they will continue to clean the floor like this. (Nurse)

However, when interviewing staff with a more in-depth knowledge of the hospital's Q\&PS projects, their views rebutted the view that aesthetics was being valued over functionality:

This is the flooring that is used in all hospitals because it is the most washable, the most hygienic, but [it is] actually also a bit slippery. (Member of the quality management department)

This quotation supports the article's main argument of the importance of understanding the interactions among the physical, social, and symbolic components of a hospital place towards Q\&PS improvement.

\section{Discussion}

This qualitative study aimed at advancing the understanding of the role of place on Q\&PS improvement by exploring the interactions between the physical, social, and symbolic dimensions of place identified by Gesler et al. (2004). In line with Heynen's (2013) conceptualization of the interactions between the physical and social/symbolic perspectives of place as space as receptor, instrument, or stage; findings suggest that the physical environment is neither a single receptor of the hospital's procedures and clinical activity; nor merely an 
1 instrument capable of changing the clinical practice and care outcomes in a pre-defined way.

2 Rather, the physical infrastructure is better understood as a stage (Heynen, 2013) which shapes,

3 and is shaped by, the social and symbolic environments.

4 By drawing on the social theory perspective of space (e.g. Gesler et al., 2004; Gieryn, 2000, 5 2002; Heynen, 2013; Lefebvre, [1974] 1991), this article thus contributes to the literature on

6 Q\&PS by connecting two distinctive but significant bodies of research: evidence-based design

7 literature, and research that focuses on how Q\&PS is realised and managed but which does not

8 explicitly consider the role of space. This goes in line with previous studies calls for the need of

9 integrating evidence-based design with knowledge about the social dimension of a hospital place

10 (e.g. Curtis et al., 2013; McLaughlan, 2017).

11 In the case study, the physical characteristics of the hospital buildings (e.g. slippery floor

12 coverings, unevenness of the floor) directly impacted on care outcomes (e.g. patient falls). This

13 is consistent with the well-developed body of research rooted in architecture, environmental

14 psychology and medicine (Zimring et al., 2013), which aims at identifying the impact of the built

15 environment on patient care and staff outcomes and propose evidence-based designs (e.g.

16 Hignett et al., 2015; Ulrich, 1984; Ulrich et al., 2008). In practice, this instrumental view of

17 space, which overlooks the influence of social and symbolic aspects, has informed the

18 development of a series of research-based guidelines on the design, planning and refurbishment

19 of healthcare facilities (e.g. American Institute of Architects Committee on Architecture for

20 Health, 1987; Department of Health, 2009).

21 Findings from the hospital also highlighted that the built environment (e.g. granite structure,

22 ward layout) shaped how Q\&PS was managed and realised inside of the hospital. For example,

23 the limitations of the physical infrastructure influenced the focus and scope of Q\&PS 
1 improvement projects, including refurbishment works. Yet, these were also determined by organisational processes such as budget allocation decisions. This is consistent with Fox's (1997)

3 ethnographic study of operating theatres which points out that the physical infrastructure, which

4 frames the circuits followed by staff, instruments and patients by offering cues on how staff 5 might behave; was itself shaped by the surgical practices at the time of the construction.

6 Similarly, although the layout of the wards impacted on how Q\&PS is realised (e.g. by allowing 7 or constraining staff's closely monitoring of patients), the realisation of Q\&PS depended on 8 organisational processes (e.g. staff/patient ratio), staff's attitudes, patient's behaviours and the 9 hospital's cultural significance of Q\&PS. In the case study hospital, underlying the symbolism of 10 closer monitoring associated with the possibility of seeing patients was the impact that 11 clinicians' surveillance of patients would have on patients' behaviours (e.g. frail patients 12 refraining from getting up from the bed by themselves). This is in line with Iedema and Rhodes 13 (2010) which found that the possibility of clinicians' to 'be seen' through video surveillance not only resulted on a form of social control but also helped them to reflect on their own practices.

15 This article thus complements a considerable number of social science studies which have 16 analysed the impact of organisational and professional interactions on Q\&PS improvement, but 17 failed to take into account the explicit role of place. Topics researched include the role of 18 informal backstage knowledge sharing on Q\&PS (e.g. Waring and Bishop, 2010), and the 19 influence that social control mechanisms adopted within the medical profession (e.g. Bosk, 202003 ) and institutionalised informal ways of dealing with doctor's underperformance (e.g. 21 Rosenthal, 1995) have on Q\&PS. Future studies could explore the influence of place on the 22 design and implementation of other specific and/or overarching Q\&PS initiatives (e.g. hospital 
1 accreditation, lean, six sigma, etc.) and include hospitals with different characteristics (e.g.

2 private, smaller, more recent, etc.).

3 Finally, evidence from the case study highlighted how the opening date of each of the buildings

4 unconsciously shaped staff's symbolic projections and expectations attributed to each of the

5 buildings, which in turn mediated staff's reactions towards the buildings' limitations and Q\&PS

6 projects adopted. The striking differences between clinicians' expectations on the new building

7 and its infrastructural limitations and the explanation of those differences attributed to non-

8 clinicians' value of aesthetics over functionally, eventually led clinicians to even change their

9 views on the hospital's identity. With the construction of the new building the hospital's general

10 identity as "old, poor, a friend of the poor, a friend of people", materialised in the neoclassical

11 building; sharply contrasted with some views of the hospital as a place where there is "no

12 sensibility" for patient's disabilities or risk of falling, up to a point where some clinicians talked

13 about the hospital as "two hospitals". This apparent change on some staff's perception of the

14 hospital's identity is critical given the role of places in building both personal and social

15 identities (Williams, 2002). As Relph (1976:34) argues, "people are their place and a place is its

16 people". Given that "place identities affiliate the self with significant locales, bringing a sense of

17 belonging and order to one's sociospatial world" (Cuba and Hummon, 1993:113), such a

18 significant change in the perceived hospital's identity is expected to challenge staff's own

19 identity.

20 This article thus contributes to the literature on the symbolic dimension of a hospital

21 environment which has received little consideration (Gesler et al., 2004; Papoulias et al., 2014)

22 and has primarily focused on patient's perspectives (e.g. Adams et al., 2010; Meriläinen et al.,

23 2010). Additionally, whereas some of the previous studies explored the impact of space on 
1 clinicians' identities (Ainsworth, Grant, \& Iedema, 2009; Halford and Leonard, 2003), findings

2 from this study extend this by highlighting the role of the built environment on framing an

3 organisation's own identity and how this identity is perceived by staff. Further research is needed

4 on how patients and different professional groups perceive a hospital and how this impacts on

5 clinical, staff, and organisational outcomes.

6 Although this study contributes to the scant literature on how place impacts on Q\&PS, it is worth 7 mentioning that the qualitative methodology adopted is not without limitations. The case study

8 was conducted in one single hospital with a distinctive built environment and focused on Q\&PS

9 initiatives (falls prevention, improvement of the hospital's accessibility) in which the built

10 environment often plays a key role, hence limiting the transferability of findings to other

11 healthcare contexts. As a result, when planning to use the conclusions drawn in this study to

12 inform practices in other settings, the contextual differences need to be taken into account.

13 Notwithstanding the limitations of the study, its main conclusion regarding the importance of

14 considering the interactions between the physical, social, and symbolic dimensions of a

15 hospital's place on Q\&PS improvement initiatives is transferable to a series of contexts.

References

Adams, A., Theodore, D., Goldenberg, E., McLaren, C., and McKeever, P. 2010. Kids in the

19 atrium: Comparing architectural intentions and children's experiences in a pediatric hospital lobby. Social Science \& Medicine, 70(5): 658-667. 
Ainsworth, S., Grant, D., \& Iedema, R. (2009). 'Keeping things moving': Space and the

2 construction of middle management identity in a post-NPM organization'. Discourse \&

3 Communication, 3, 5-25.

American Institute of Architects Committee on Architecture for Health 1987. Guidelines for construction and equipment of hospitals and medical facilities. Washington, D.C.: The American Institute of Architects Press.

Anderson, B. (2008). In Hubbard P., Valentine G. and Kitchin R.(Eds.), For Space (2005): Doreen Massey. London: Sage.

Andrews, G. J., and Evans, J. 2008. Understanding the reproduction of health care: Towards geographies in health care work. Progress in Human Geography, 32(6): 759-780.

Braun, V., and Clarke, V. 2006. Using thematic analysis in psychology. Qualitative Research in Psychology, 3(2): 77-101.

Bosk, C. L. (2003). Forgive and remember: Managing medical failure. Chicago: University of Chicago Press.

Buffoli, M., Nachiero, D., and Capolongo, S. 2012. Flexible healthcare structures: Analysis and evaluation of possible strategies and technologies. Annali di Igiene: Medicina Preventiva e di Comunità, 24(6): 543-552.

Casey, E. S. 1996. How to get from space to place in a fairly short stretch of time. In S. Feld and K. H. Basso (Ed.), Senses of Place, vol. 27: 13-51. Santa Fé: School of American Research Press.

Cuba, L., and Hummon, D. M. 1993. A place to call home: Identification with dwelling, community, and region. The Sociological Quarterly, 34(1): 111-131. 
Curtis, S., Gesler, W., Wood, V., Spencer, I., Mason, J., Close, H., and Reilly, J. 2013.

2 Compassionate containment? balancing technical safety and therapy in the design of psychiatric 3 wards. Social Science \& Medicine, 97: 201-209.

Department of Health 2009. Adult in-patient facilities: Planning and design (HBN 04-01).

London: UK Department of Health.

Donabedian, A., and Bashshur, R. 2003. An introduction to quality assurance in health care.

Oxford: Oxford University Press.

Dovey, K. 2010. Becoming places: Urbanism/architecture/identity/power. Abingdon:

9 Routledge.

Flick, U. 2007. Managing quality in qualitative research. Los Angeles; London: Sage

11 Publications.

Fox, N. J. 1997. Space, sterility and surgery: Circuits of hygiene in the operating theatre.

Social Science \& Medicine, 45(5): 649-657.

Clinicians' use of space and bodies during diagnosis. Sociology of Health \& Illness, 37(5): 765 781.

Gesler, W., Bell, M., Curtis, S., Hubbard, P., and Francis, S. 2004. Therapy by design:

Evaluating the UK hospital building program. Health \& Place, 10(2): 117-128.

Gieryn, T. F. 2002. What buildings do. Theory and Society, 31(1): 35-74. 
Gorbenko, K. O., Brooks, J. V., Van De Ruit, C., Ju, M. H., Hobson, D. B., Holzmueller, C.

2 G., Pronovost, P. J., Ko, C. Y., Bosk, C. L., and Wick, E. C. 2015. Sustaining quality

3 improvement during data lag: A qualitative study in a perioperative setting. Perioperative Care

4 and Operating Room Management, 1(1): 2-8.

Halford, S., and Leonard, P. 2003. Space and place in the construction and performance of gendered nursing identities. Journal of Advanced Nursing, 42(2): 201-208.

Harvey, D. (1996). Justice, nature and the geography of difference. Cambridge, MA: Blackwell.

Heynen, H. 2013. Space as receptor, instrument or stage: Notes on the interaction between spatial and social constellations. International Planning Studies, 18(3-4): 342-357.

Hignett, S., Wolf, L., Taylor, E., and Griffiths, P. 2015. Firefighting to innovation: Using human factors and ergonomics to tackle slip, trip, and fall risks in hospitals. Human Factors, 57(7): 1195-1207. Nursing Management, 19(4): 439-448. surveillance'. Organization Studies, 31, 199-217. Lefebvre, H. [1974] 1991. The production of space. Oxford: Blackwell. Mallak, L. A., Lyth, D. M., Olson, S. D., Ulshafer, S. M., and Sardone, F. J. 2003. Culture, the built environment and healthcare organizational performance. Managing Service Quality: An 21 International Journal, 13(1): 27-38. 
1 Martin, D., Nettleton, S., Buse, C., Prior, L., and Twigg, J. 2015. Architecture and health care: A place for sociology. Sociology of Health \& Illness, 37(7), 1007-1022.

Massey, D. 1994. Space, place and gender. Cambridge: Polity Press.

McLaughlan, R. 2017. Psychosocially supportive design: The case for greater attention to social space within the pediatric hospital. HERD: Health Environments Research \& Design Journal, 1-12.

Meriläinen, M., Kyngäs, H., and Ala-Kokko, T. 2010. 24-hour intensive care: An observational study of an environment and events. Intensive and Critical Care Nursing, 26(5): 246-253.

Mesman, J. 2012. Moving in with care about patient safety as a spatial achievement. Space

11 and Culture, 15(1): 31-43.

Moreira, T. 2004. Coordination and embodiment in the operating room. Body \& Society, 13 10(1): 109-129.

Papoulias, C., Csipke, E., Rose, D., McKellar, S., and Wykes, T. 2014. The psychiatric ward as a therapeutic space: Systematic review. The British Journal of Psychiatry: The Journal of Mental Science, 205(3): 171-176.

Reason, J. 2016. Managing the risks of organizational accidents. London: Routledge. 
Rossman, G. B., and Rallis, S. F. 2003. Learning in the field: An introduction to qualitative research. Thousand Oaks, Calif.; London: Sage Publications.

Sullivan, N. 2012. Enacting spaces of inequality: Placing global/state governance within a

4 Tanzanian hospital. Space and Culture, 15(1): 57-67.

Thrift, N. (1996). Spatial formations. London: Sage.

Ulrich, R. 1984. View through a window may influence recovery. Science, 224(4647): 224225.

Ulrich, R. S., Zimring, C., Zhu, X., DuBose, J., Seo, H., Choi, Y., Quan, X., and Joseph, A. 2008. A review of the research literature on evidence-based healthcare design. HERD: Health Environments Research \& Design Journal, 1(3): 61-125.

11 Waring, J. J., and Bishop, S. 2010. "Water cooler" learning: Knowledge sharing at the 12 clinical "backstage" and its contribution to patient safety. Journal of Health Organization and 13 Management, 24(4): 325-342.

14 Webb, C. 1999. Analysing qualitative data: Computerized and other approaches. Journal of Advanced Nursing, 29(2): 323-330. Williams, A. 2002. Changing geographies of care: Employing the concept of therapeutic 17 landscapes as a framework in examining home space. Social Science \& Medicine, 55(1): 141154. patient conflicts in china's hospital therapeutic landscapes. Health \& Place, 42: 137-147. 
1 Zimring, C., Denham, M. E., Jacob, J. T., Cowan, D. Z., Do, E., Hall, K. et al. (2013).

2 'Evidence-based design of healthcare facilities: Opportunities for research and practice in 3 infection prevention'. Infection Control and Hospital Epidemiology, 34, 514-6.

4

5 